\title{
Enhancing the Catalytic Activity of Tri-iodide Reduction by Tuning the Surface Electronic Structure of PtPd alloy Nanocrystals
}

Keh-Jiunh Chou, ${ }^{\text {a }}$ Shang-Wei Chou,,${ }^{\mathrm{a}}{ }^{*}$ Deng-Gao Chen, ${ }^{\mathrm{a}}$ Tzu-Hsuan Lo, ${ }^{\mathrm{a}}$ Shin-Wei Shen, ${ }^{\mathrm{b}}$ Ya-Yun Yang, ${ }^{\mathrm{c}}$ Ching-Yen Lin, ${ }^{\mathrm{c}}$ Hung-Lung Chou, ${ }^{\mathrm{d},{ }^{*}}$ Jing-Jong Shyue,,${ }^{\mathrm{e},}$ Chih-I Wu, ${ }^{\text {b }}$ and Pi-Tai Chou ${ }^{\mathrm{a}, \mathrm{f}, *}$

a Department of Chemistry, National Taiwan University, Taipei, Taiwan, 10617;

${ }^{\mathrm{b}}$ Graduate Institute of Photonics and Optoelectronics, National Taiwan University, Taipei, Taiwan, 10617;

c Instrumentation Center, National Taiwan University, Taipei, Taiwan, 10617;

d Graduate Institute of Applied Science \& Technology, National Taiwan University of Science and Technology, Taipei, Taiwan, 10607;

e Research Center for Applied Sciences, Academia Sinica, Taipei, Taiwan, 11529;

${ }_{\mathrm{f}}$ Center for Emerging Material and Advanced Devices, National Taiwan University, Taipei, Taiwan, 10617;

\section{Corresponding Author}

Prof. Pi-Tai Chou, email: chop@ntu.edu.tw

Dr. Jing-Jong Shyue, email: shyue@gate.sinica.edu.tw

Prof. Hung-Lung Chou, email: HLCHOU@mail.ntust.edu.tw

Dr. Shang-Wei Chou, email: sweichou@gmail.com 


\section{Table of Content}

\section{Supplementary Figures:}

Figure S1: X-ray energy-dispersive spectra (EDS) of PtPdNCs.

Figure S2: Particle size distribution of PtPd NCs

Figure S3: HRTEM images of (111) plane of PtPd NCs S5

Figure S4: Comparison between TEM images of $\mathrm{Pt}_{5} \mathrm{Pd}_{5}$ nanocrystals before and after annealing .S6

Figure S5: Tafel curves of three-zone diagram. S6

Figure S6: The volcano-shaped trends of $J_{0}, J_{\text {lim }}$ and $1 / \mathrm{R}_{\mathrm{ct} 1}$ for different PtPd NCs ...S7

Figure S7: Calculation on reduction process of $\boldsymbol{I}_{3}{ }^{-}$to $\boldsymbol{I}^{-}$on CE........................S8

Figure S8: Theoretical model of PtPd (111) planes S9

Figure S9: Theoretical model of $\mathbf{I}_{\mathbf{2}} / \mathrm{PtPd}$ (111) planes. S9

Figure S10: Theoretical model of $\mathbf{I}^{-} / \mathrm{PtPd}(111)$ planes $\mathrm{S} 10$

\section{Supplementary Tables:}

Table S1. The synthetic parameters of PtPd NCs

Table S2. Summarization of the $J_{s c}$ and $J_{I P C}$ values obtained from Figure $3 \mathrm{~b}$ and $3 \mathrm{cS} 11$

Table S3. Other fitting parameters of impedance data obtained from EIS measurements.

Table S4. Table shown that optimized distances of Pt-Pt, Pt-Pd, Pt-I species in the Pt$\operatorname{Pd}(111)$ alloy systems, respectively.

Table S5. Summary of adsorption energies of $\boldsymbol{I}_{\mathbf{2}}$, desorption energies of $\boldsymbol{I}^{-}$, corresponding absolute energies and optimized geometries calculation 
(a)

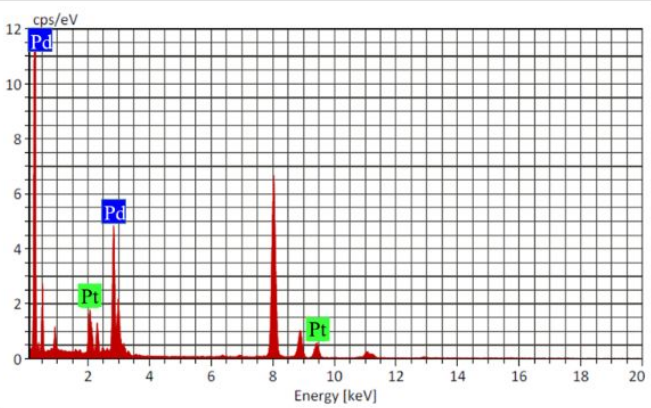

(b)

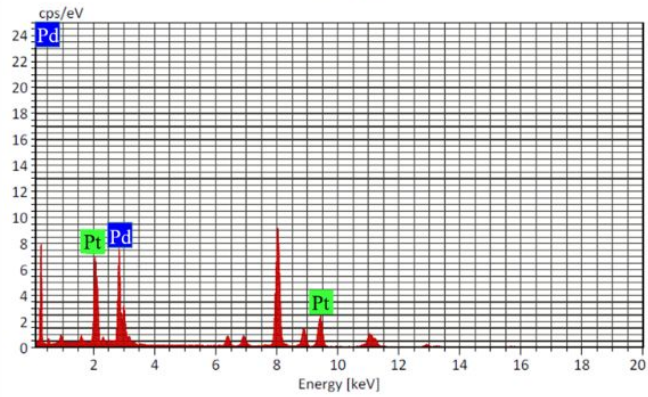

(c)

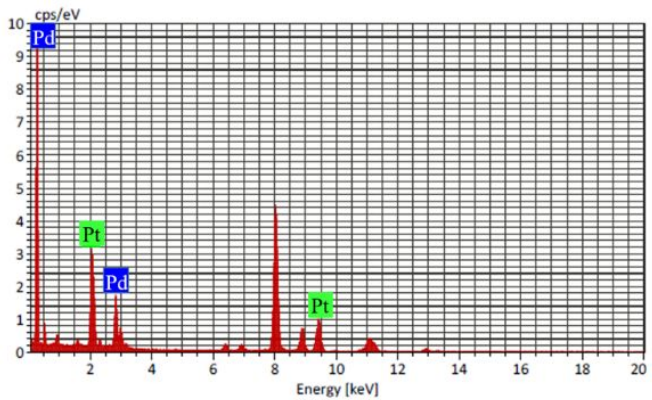

(d)

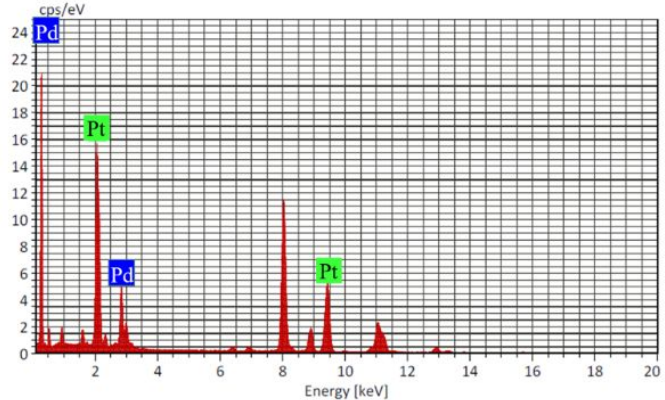

\section{Elements Weight \% Atomic \%}

\begin{tabular}{|c|c|c|}
\hline $\mathrm{Pd}$ & 80.6 & 88.4 \\
\hline $\mathrm{Pt}$ & 19.4 & 11.6 \\
\hline Total & 100.0 & 100.0 \\
\hline
\end{tabular}

\section{Elements $\quad$ Weight \% 1 Atomic \%}

\begin{tabular}{|c|c|c|}
\hline $\mathrm{Pd}$ & 51.6 & 66.1 \\
\hline $\mathrm{Pt}$ & 48.4 & 33.9 \\
\hline Total & 100.0 & 100.0 \\
\hline
\end{tabular}

Elements Weight \% Atomic \%

\begin{tabular}{|c|c|c|}
\hline $\mathrm{Pd}$ & 38.0 & 52.9 \\
\hline $\mathrm{Pt}$ & 62.0 & 47.1 \\
\hline Total & 100.0 & 100.0 \\
\hline
\end{tabular}

Elements Weight \% Atomic \%

\begin{tabular}{|c|c|c|}
\hline $\mathrm{Pd}$ & 21.9 & 33.9 \\
\hline $\mathrm{Pt}$ & 78.1 & 66.1 \\
\hline Total & 100.0 & 100.0 \\
\hline
\end{tabular}

Figure S1. X-ray energy-dispersive spectra (EDS) of (a) $\mathrm{Pt}_{1} \mathrm{Pd}_{9} \mathrm{NCs}$, (b) $\mathrm{Pt}_{3} \mathrm{Pd}_{7} \mathrm{NCs}$, (c) $\mathrm{Pt}_{5} \mathrm{Pd}_{5} \mathrm{NCs}$, and (d) $\mathrm{Pt}_{7} \mathrm{Pd}_{3} \mathrm{NCs}$. 

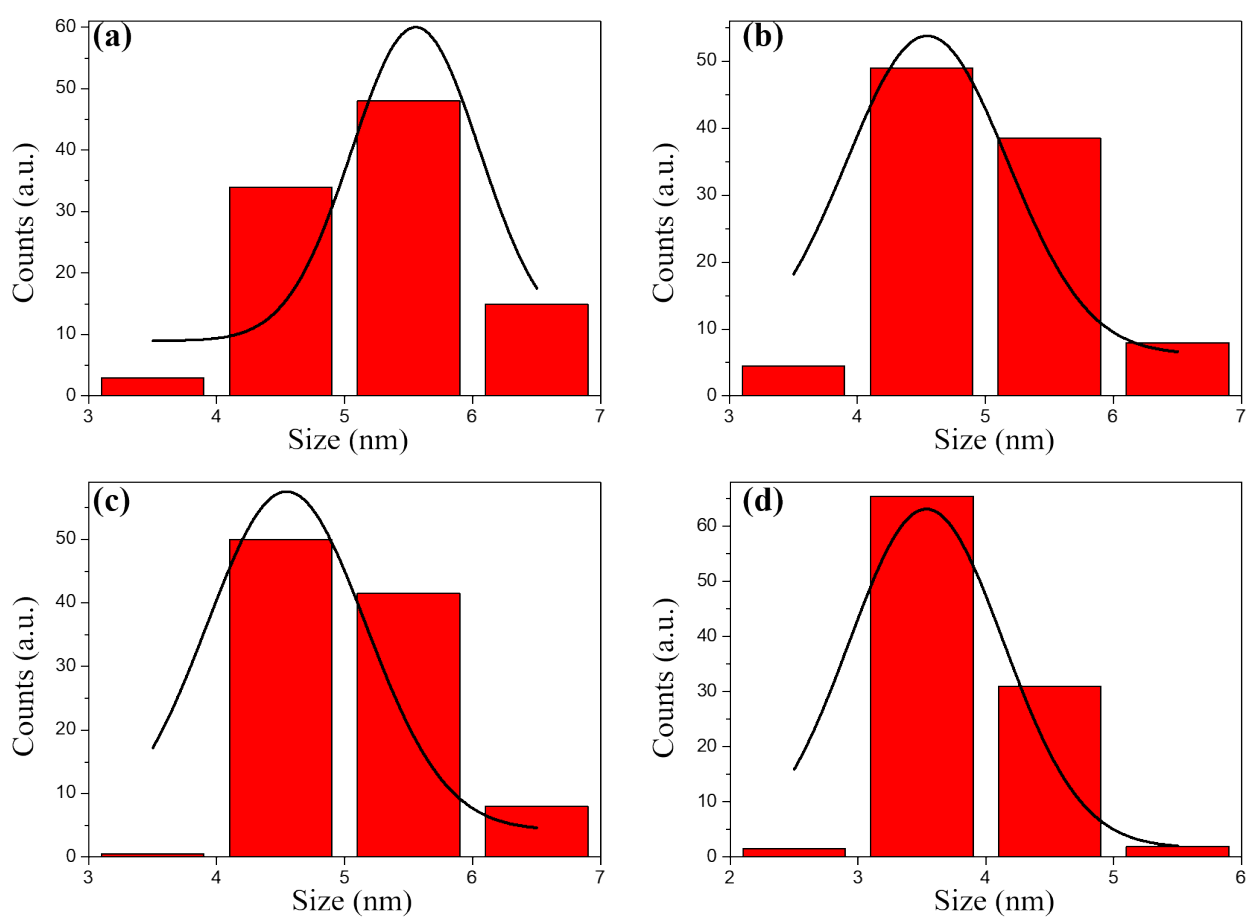

Figure S2. The particle size distributions of (a) $\mathrm{Pt}_{1} \mathrm{Pd}_{9} \mathrm{NCs}$, (b) $\mathrm{Pt}_{3} \mathrm{Pd}_{7} \mathrm{NCs}$, (c) $\mathrm{Pt}_{5} \mathrm{Pd}_{5}$ $\mathrm{NCs}$, and (d) $\mathrm{Pt}_{7} \mathrm{Pd}_{3} \mathrm{NCs}$. 
(a)

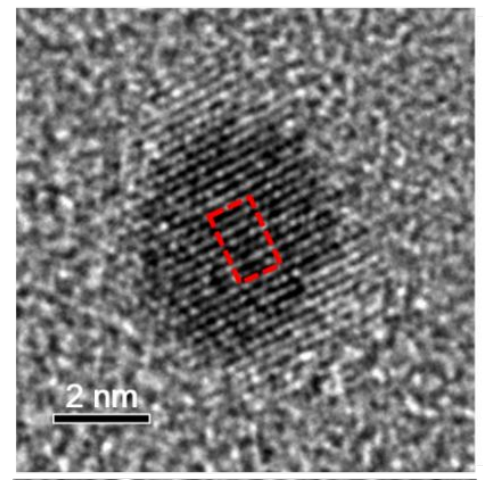

(b)

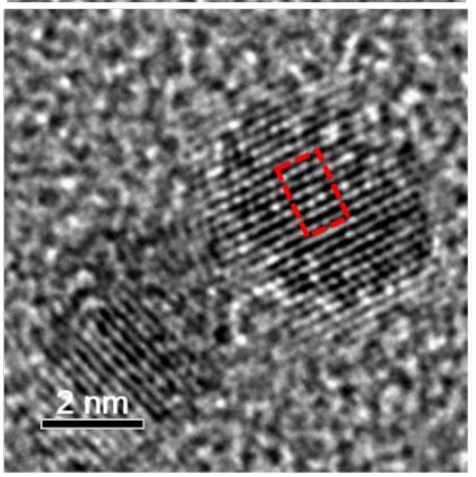

(c)

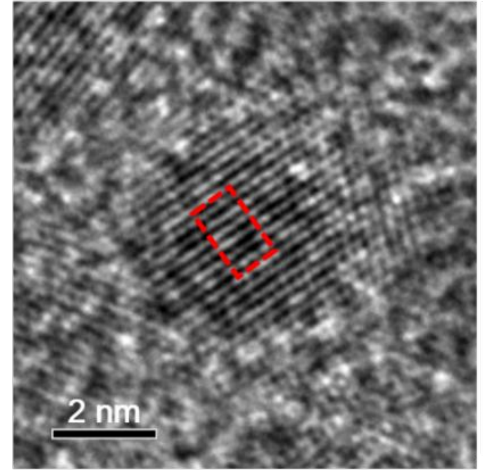

(d)

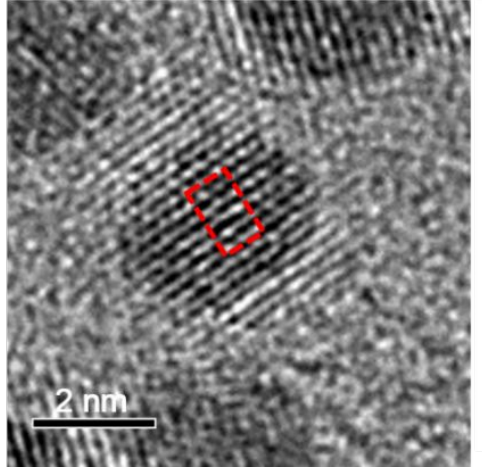

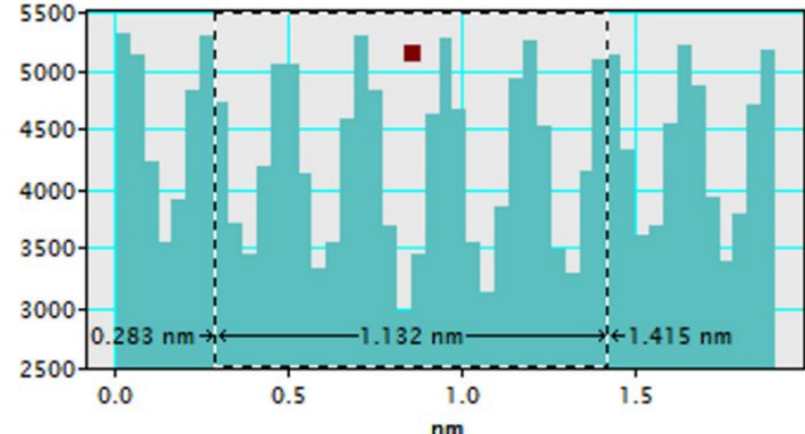
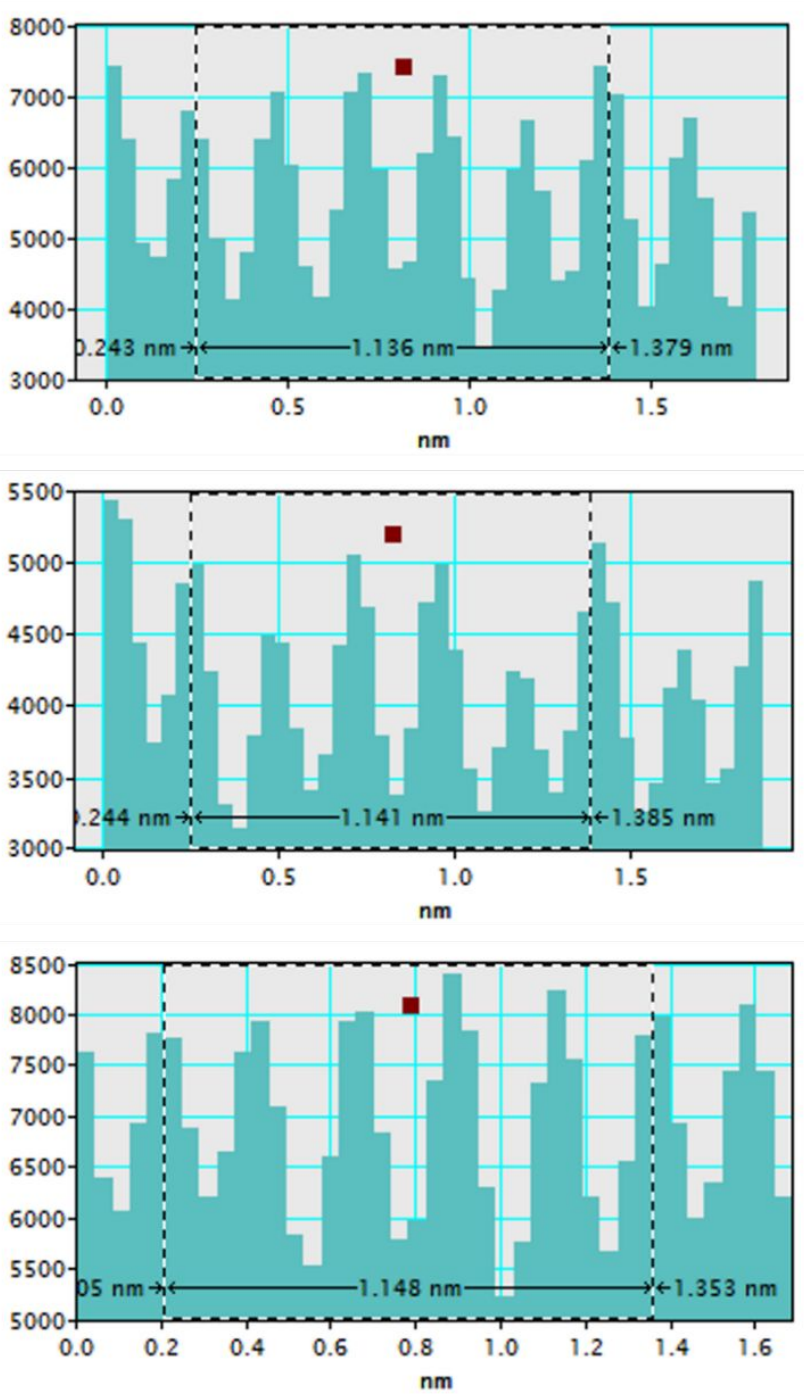

Figure S3. HRTEM images of nanocrystals of (a) $\mathrm{Pt}_{1} \mathrm{Pd}_{9}$ (111) plane, (b) $\mathrm{Pt}_{3} \mathrm{Pd}_{7}$ (111) plane, (c) $\mathrm{Pt}_{5} \mathrm{Pd}_{5}$ (111) plane, and (d) $\mathrm{Pt}_{7} \mathrm{Pd}_{3}$ (111) plane. The calculated results (as shown in the below row) is obtained through the analysis of selected area with 5 intervals, presenting the lattice distances of (111) surface of PtPd NCs with different alloying compositions. 


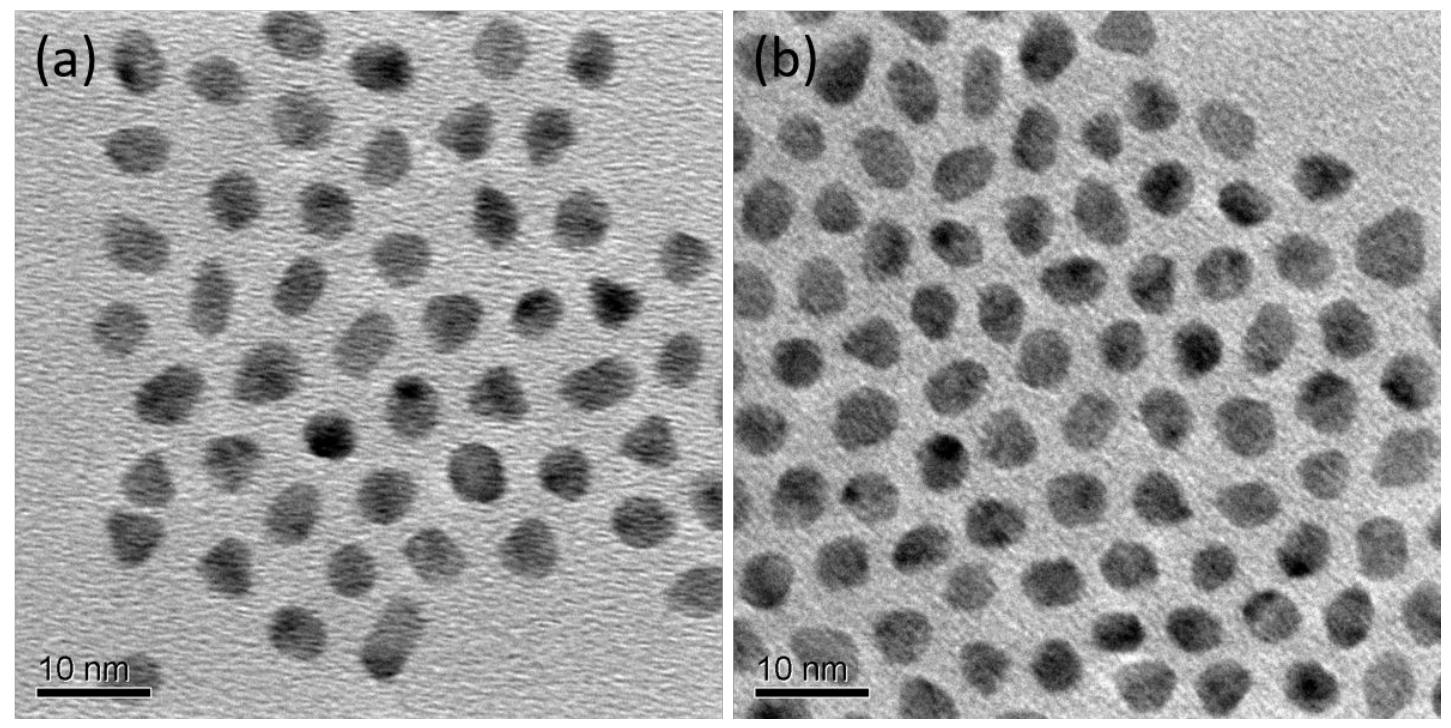

Figure S4. (a) The TEM image of annealed $\mathrm{Pt}_{5} \mathrm{Pd}_{5}$ nanocrystals $\left(350^{\circ} \mathrm{C}\right.$ in oxygen and then hydrogen) (b) The TEM image of $\mathrm{Pt}_{5} \mathrm{Pd}_{5}$ nanocrystals before annealing.

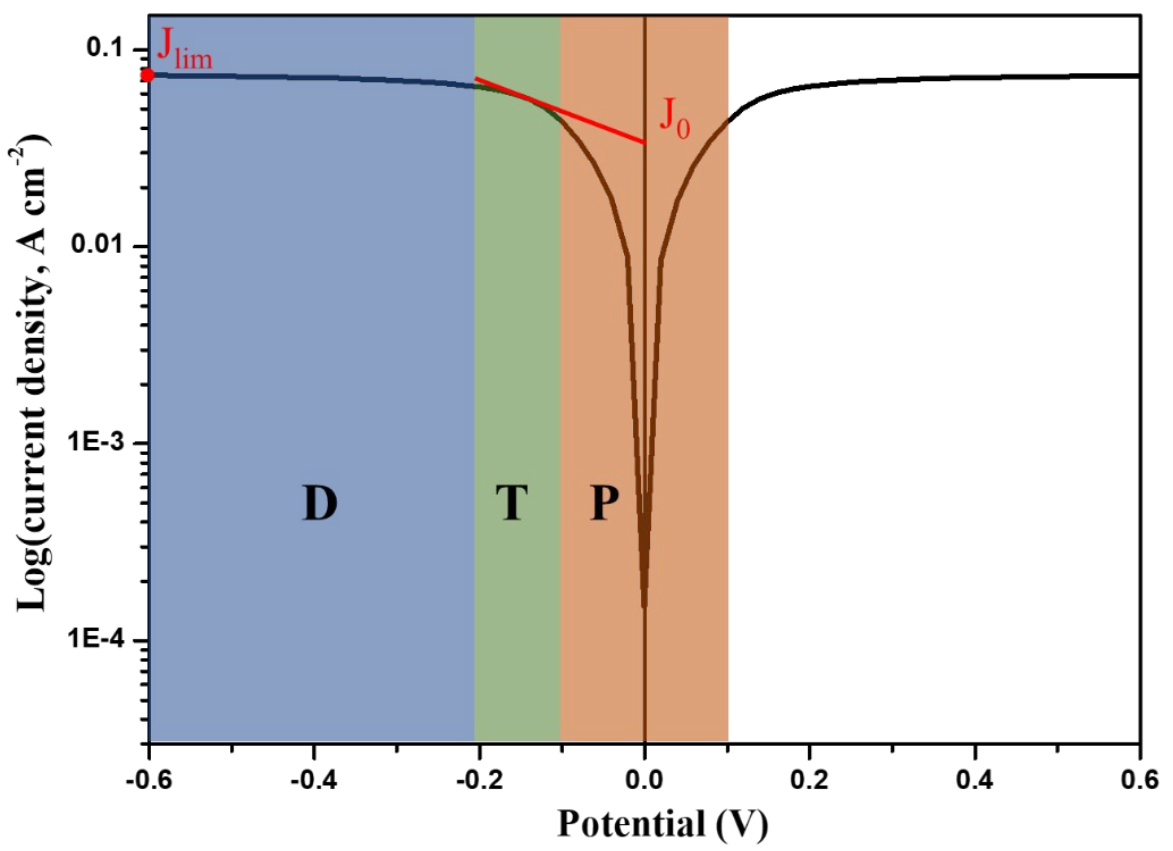

Figure S5. Tafel curves of three-zone diagram including (P) Polarization zone, (T) Tafel zone, (D) Diffusion zone. Furthermore, $J_{0}$ and $J_{l i m}$ were acquired as showed in graphic. 


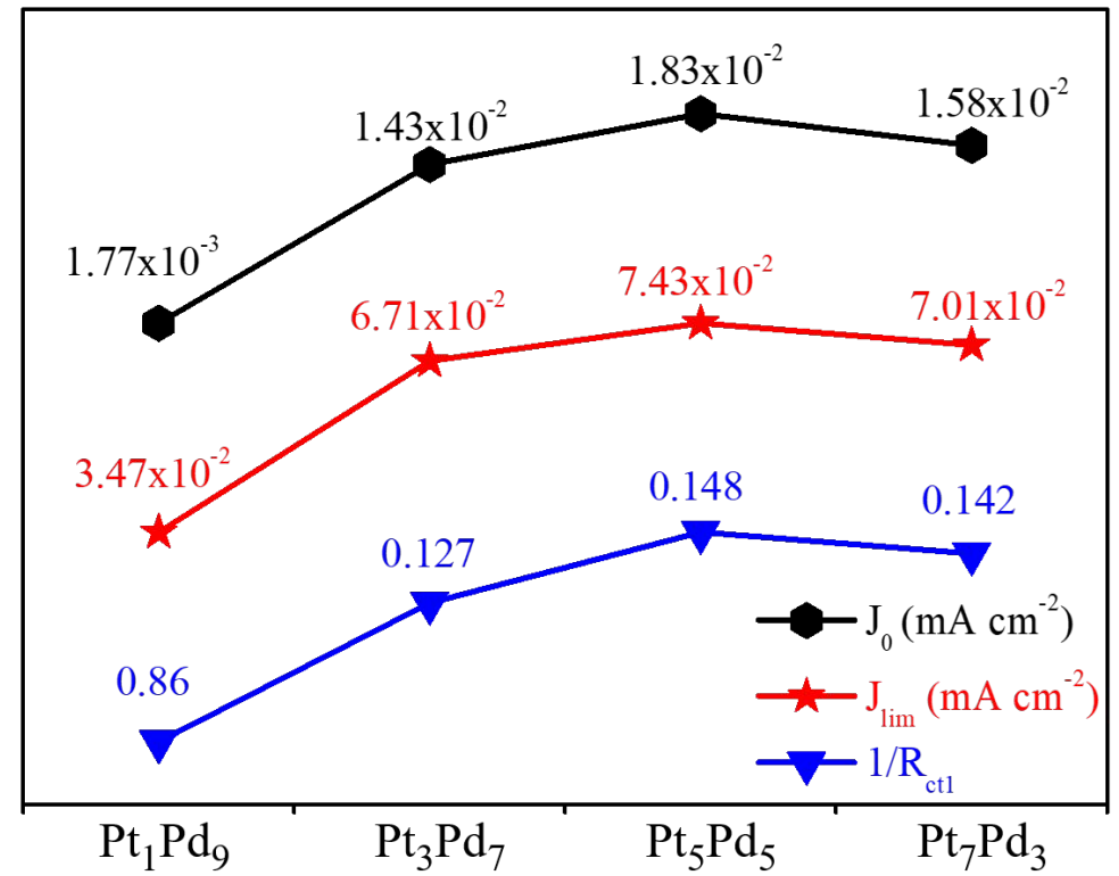

Figure S6. The volcano-shaped trends of $J_{0}, J_{\text {lim }}$ and $1 / \mathrm{R}_{\mathrm{ct} 1}$ for different alloying compositions of PtPd NCs. Note: The values labeled in the graphic are tabulated in Table 2. 
(a) $\mathrm{Pt}_{7} \mathrm{Pd}_{3}(111)$

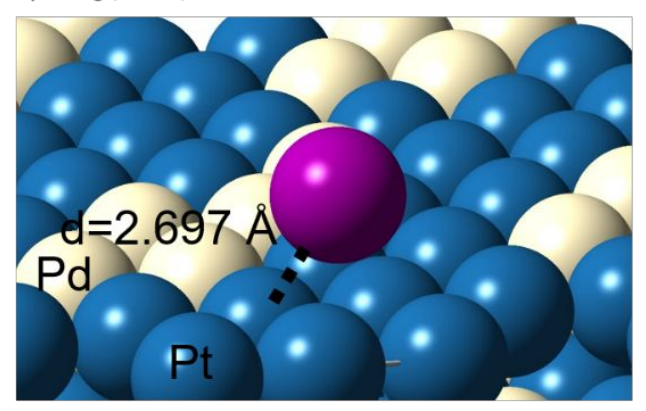

(b) $\mathrm{Pt}_{7} \mathrm{Pd}_{3}(111)$

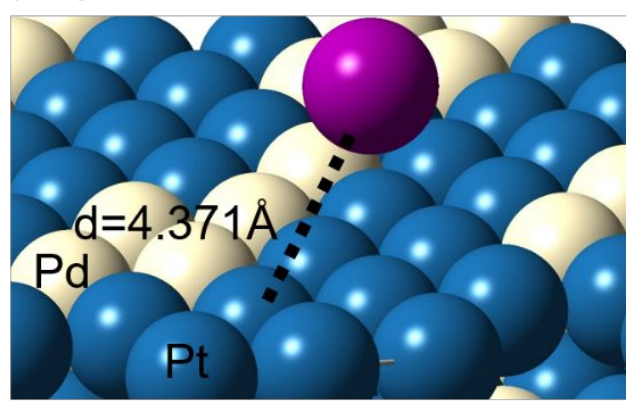

(c)

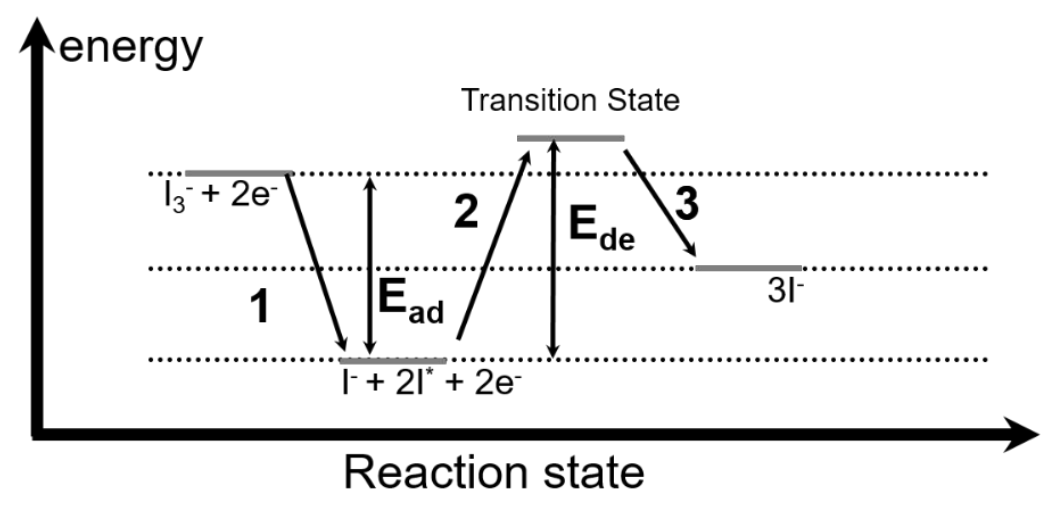

Figure S7. Calculation on reduction process of $I_{3}{ }^{-}$to $I^{-}$on CE: (a) Adsorption structure of I atom on $\mathrm{Pt}_{7} \mathrm{Pd}_{3}$ (111); $2.697 \AA$ as shown in $\mathrm{d}$ for Pt-I bond length on $\mathrm{Pt}_{7} \mathrm{Pd}_{3}$ (bridge site). Denotes that the value were recorded as $2.695 \AA$ and $2.692 \AA$ on $\mathrm{Pt}_{5} \mathrm{Pd}_{5}$ and $\mathrm{Pt}_{3} \mathrm{Pd}_{7}$, respectively. The above results were tabulated in Table S4. (b) Desorption structure of $\mathrm{I}^{-}$on $\mathrm{Pt}_{7} \mathrm{Pd}_{3}$ (111); Pt-I' bond length was recorded as $4.371 \AA$ on $\mathrm{Pt}_{7} \mathrm{Pd}_{3}$, and $4.213 \AA$ and $4.120 \AA$ were recorded on $\mathrm{Pt}_{5} \mathrm{Pd}_{5}-\mathrm{I}^{-}$and $\mathrm{Pt}_{3} \mathrm{Pd}_{7}-\mathrm{I}^{-}$, respectively. (c) Energy profile of catalysis process for $I_{3}{ }^{-} / I^{-}$system. Process 1: dissociation of $\mathrm{I}_{3}{ }^{-}$and adsorption of I atom on the electrode surface; Process 2 and process 3: reduction of I atom and desorption of $I^{-}$through the transition state.

Surface diffusion was a general process involving the motion of molecule at metal alloy surfaces. ${ }^{1}$ Surface diffusion rates and mechanisms are affected by a variety of factors including the strength of the surface-adparticle bond, orientation of the surface lattice, attraction and repulsion between surface species and gradients of chemical potential. The above descriptions are important concepts in surface phase formation, epitaxial growth, heterogeneous catalysis, and other topics in surface science. ${ }^{2}$ As a result, the iodine reduction reaction (IRR) may be regarded as a model system of a heterogeneous surface - a process involving molecular adsorption and surface reaction and desorption of products. 
(a)

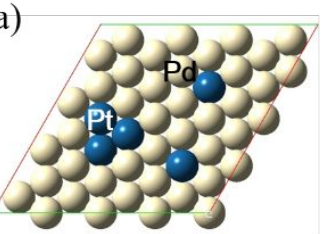

(e)

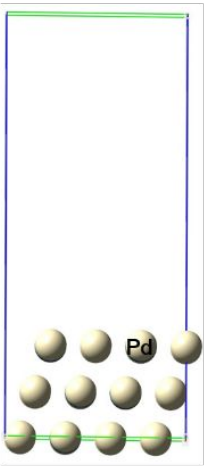

(b)

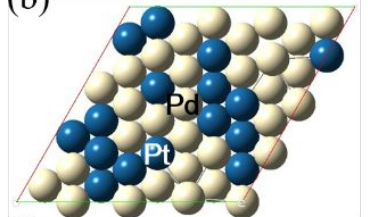

(f)

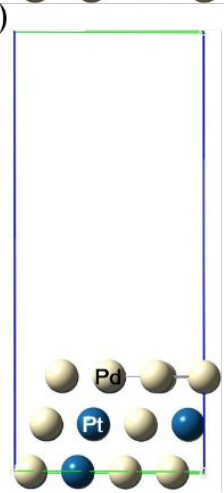

(c)

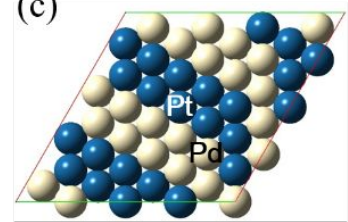

(g)

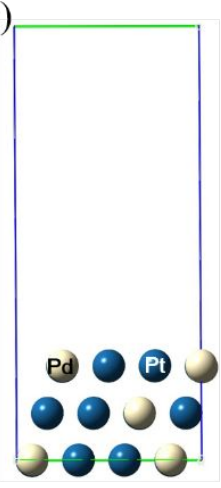

(d)

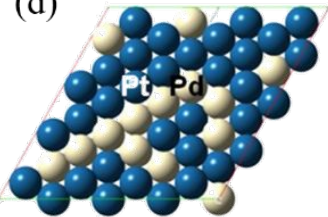

(h) 00

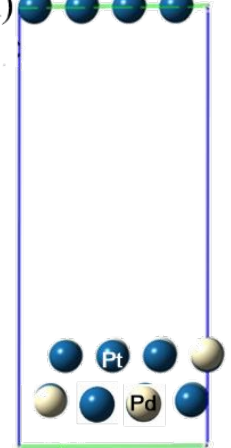

Figure S8. The model of top-view of (a) $\mathrm{Pt}_{1} \mathrm{Pd}_{9}(111)$ surface, (b) $\mathrm{Pt}_{3} \mathrm{Pd}_{7}$ (111) surface, (c) $\mathrm{Pt}_{5} \mathrm{Pd}_{5}(111)$ surface, and (d) $\mathrm{Pt}_{7} \mathrm{Pd}_{3}$ (111) surface. The side-view of (e) $\mathrm{Pt}_{1} \mathrm{Pd}_{9}$ (111) surface, (f) $\mathrm{Pt}_{3} \mathrm{Pd}_{7}$ (111) surface, (g) $\mathrm{Pt}_{5} \mathrm{Pd}_{5}$ (111) surface, and (h) $\mathrm{Pt}_{7} \mathrm{Pd}_{3}$ (111) surface.

(a)

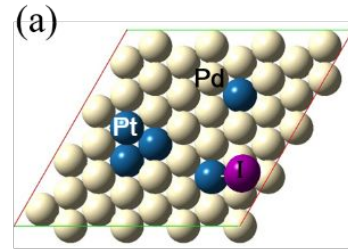

(e)

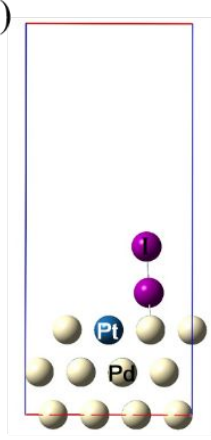

(b)

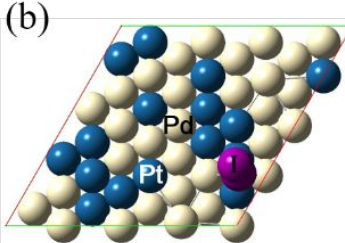

(f)

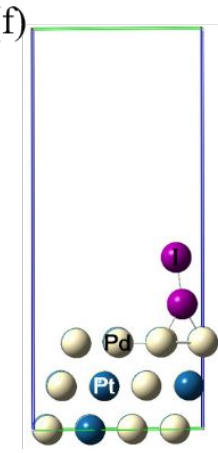

(c)

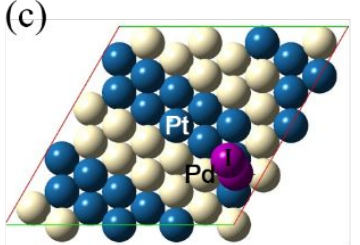

(g)

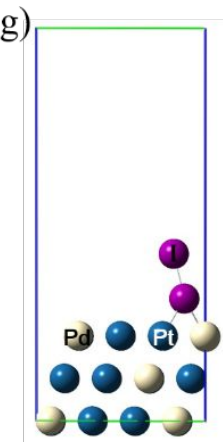

(d)

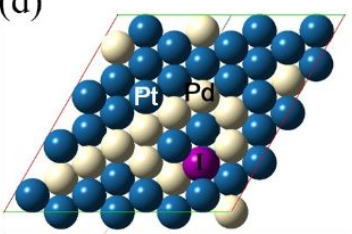

(h) 000

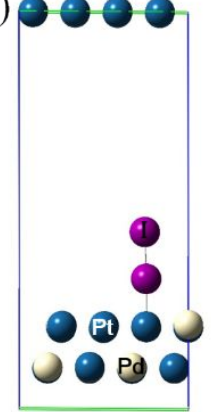

Figure S9. The model of top-view of (a) $I_{2} / \mathrm{Pt}_{1} \mathrm{Pd}_{9}(111)$ surface, (b) $\mathrm{I}_{2} / \mathrm{Pt}_{3} \mathrm{Pd}_{7}(111)$ surface, (c) $\mathrm{I}_{2} / \mathrm{Pt}_{5} \mathrm{Pd}_{5}$ (111) surface, and (d) $\mathrm{I}_{2} / \mathrm{Pt}_{7} \mathrm{Pd}_{3}$ (111) surface. The side-view of (e) $\mathrm{I}_{2} / \mathrm{Pt}_{1} \mathrm{Pd}_{9}$ (111) surface, (f) $\mathrm{I}_{2} / \mathrm{Pt}_{3} \mathrm{Pd}_{7}$ (111) surface, (g) $\mathrm{I}_{2} / \mathrm{Pt}_{5} \mathrm{Pd}_{5}$ (111) surface, and (h) $\mathrm{I}_{2} / \mathrm{Pt}_{7} \mathrm{Pd}_{3}(111)$ surface. 
(a)

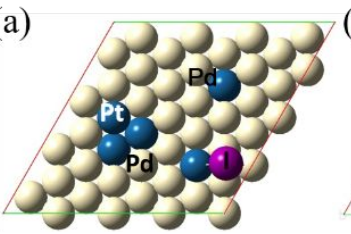

(e)

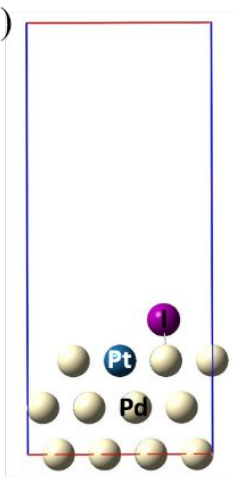

(b)

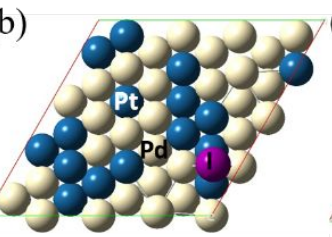

(f)

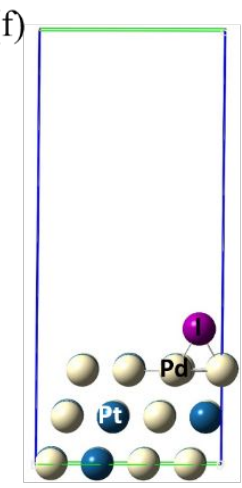

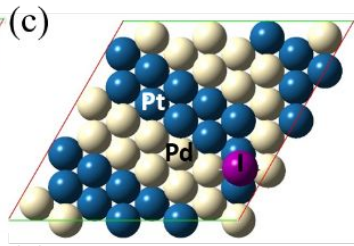

(g)

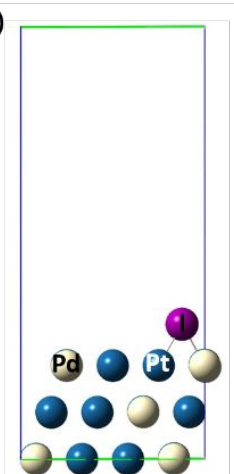

(d)

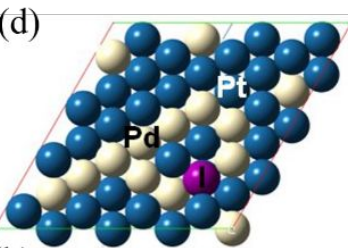

(h)

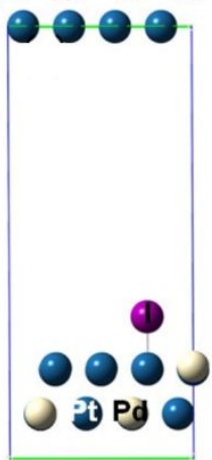

Figure S10. The model of top-view of (a) $\mathrm{I}^{-} / \mathrm{Pt}_{1} \mathrm{Pd}_{9}$ (111) surface, (b) $\mathrm{I}^{-} / \mathrm{Pt}_{3} \mathrm{Pd}_{7}$ (111) surface, (c) $\mathrm{I}^{-} / \mathrm{Pt}_{5} \mathrm{Pd}_{5}$ (111) surface, and (d) $\mathrm{I}^{-} / \mathrm{Pt}_{7} \mathrm{Pd}_{3}(111)$ surface. The side-view of (e) $\mathrm{I}^{-} / \mathrm{Pt}_{1} \mathrm{Pd}_{9}$ (111) surface, (f) $\mathrm{I}^{-} / \mathrm{Pt}_{3} \mathrm{Pd}_{7}$ (111) surface, (g) $\mathrm{I}^{-} /$ $\mathrm{Pt}_{5} \mathrm{Pd}_{5}(111)$ surface, and (h) $\mathrm{I}^{-} / \mathrm{Pt}_{7} \mathrm{Pd}_{3}(111)$ surface. 
Table S1. The experimental parameters for the synthesis of PtPd NCs with different alloying compositions.

\begin{tabular}{ccccc}
\hline Sample & Pt(acac) & Pd(acac) & MB & OLAm \\
\hline $\mathrm{Pt}_{1} \mathrm{Pd}_{9} \mathrm{NC}$ & $19.7 \mathrm{mg}$ & $76.1 \mathrm{mg}$ & $200 \mathrm{mg}$ & $3 \mathrm{~mL}$ \\
$\mathrm{Pt}_{3} \mathrm{Pd}_{7} \mathrm{NC}$ & $49.2 \mathrm{mg}$ & $76.1 \mathrm{mg}$ & $200 \mathrm{mg}$ & $3 \mathrm{~mL}$ \\
$\mathrm{Pt}_{5} \mathrm{Pd}_{5} \mathrm{NC}$ & $98.3 \mathrm{mg}$ & $76.1 \mathrm{mg}$ & $200 \mathrm{mg}$ & $3 \mathrm{~mL}$ \\
$\mathrm{Pt}_{7} \mathrm{Pd}_{3} \mathrm{NC}$ & $196.6 \mathrm{mg}$ & $76.1 \mathrm{mg}$ & $200 \mathrm{mg}$ & $3 \mathrm{~mL}$ \\
\hline
\end{tabular}

All reactants were loaded into $15 \mathrm{~mL}$ OLAm for synthetic reaction.

Table S2. Summarization of the $J_{s c}$ obtained in the $J-V$ curve of Figure $\mathbf{3 b}$ and the $J_{I P C}$ values from IPCE spectra (Figure 3c). Besides, the $J_{I P C}$ values are calculated by integrating the IPCE spectra with a standard AM 1.5G solar spectrum, by the following equation :

$$
I=\int \frac{1}{1240} \lambda \cdot \operatorname{IPCE}(\lambda) \cdot E(\lambda) \mathrm{d} \lambda
$$

where IPCE $(\lambda)$ is the acquired IPCE profile as a function of wavelengths $(\lambda)$ and $E(\lambda)$ is the solar spectral irradiance at a specific wavelength $(\lambda)$. The difference between integrated current $\left(J_{I P C}\right)$ and measured current $\left(J_{s c}\right)$ is mainly ascribed to the spectral mismatches between our solar simulator and the standard AM1.5G sunlight.

\begin{tabular}{ccc}
\hline $\begin{array}{c}\text { Counter } \\
\text { electrode }\end{array}$ & $\begin{array}{c}\boldsymbol{J}_{\mathbf{S C}} \\
\text { (measured in the } \mathbf{J}-\mathbf{V} \\
\text { curve) }\end{array}$ & $\begin{array}{c}\boldsymbol{J}_{\text {IPC }} \\
\text { (integrated from IPCE } \\
\text { spectrum) }\end{array}$ \\
\hline $\mathrm{Pt}_{5} \mathrm{Pd}_{5} \mathrm{NC}$ & $20 \pm 1 \mathrm{~mA} / \mathrm{cm}^{2}$ & $17.53 \mathrm{~mA} / \mathrm{cm}^{2}$ \\
$\mathrm{Pt}$ thin film & $15.8 \pm 0.6 \mathrm{~mA} / \mathrm{cm}^{2}$ & $13.26 \mathrm{~mA} / \mathrm{cm}^{2}$ \\
\hline
\end{tabular}

Table S3. Other fitting parameters of impedance data obtained from EIS measurements.

\begin{tabular}{lccccc}
\hline \multicolumn{1}{c}{$\mathbf{C E}$} & $\begin{array}{c}\mathbf{R}_{\mathbf{c t} 2} \\
{[\Omega]}\end{array}$ & $\begin{array}{c}\mathbf{R}_{\mathbf{c t 3}} \\
{[\Omega]}\end{array}$ & $\begin{array}{c}\mathbf{C P E} \\
{[\mu \mathrm{F}]}\end{array}$ & $\begin{array}{c}\mathbf{C P E} \\
{[\mu \mathrm{F}]}\end{array}$ & $\begin{array}{c}\mathbf{C P E}_{\mathbf{3}} \\
{[\mu \mathrm{F}]}\end{array}$ \\
\hline Pt thin film & 13.56 & 18.56 & $1.21 \times 10^{-4}$ & $9.97 \times 10^{-4}$ & $5.79 \times 10^{-3}$ \\
$\mathrm{Pt}_{1} \mathrm{Pd}_{9}$ & 23.52 & 24.37 & $6.06 \times 10^{-5}$ & $1.63 \times 10^{-2}$ & $7.19 \times 10^{-4}$ \\
$\mathrm{Pt}_{3} \mathrm{Pd}_{7}$ & 16.88 & 23.92 & $8.35 \times 10^{-5}$ & $1.19 \times 10^{-2}$ & $5.15 \times 10^{-4}$ \\
$\mathrm{Pt}_{5} \mathrm{Pd}_{5}$ & 13.66 & 19.8 & $6.65 \times 10^{-5}$ & $2.56 \times 10^{-2}$ & $6.74 \times 10^{-4}$ \\
$\mathrm{Pt}_{7} \mathrm{Pd}_{3}$ & 14.65 & 25.78 & $8.29 \times 10^{-5}$ & $2.38 \times 10^{-2}$ & $6.33 \times 10^{-4}$ \\
\hline
\end{tabular}


Table S4. Table shown that optimized distances of Pt-Pt, Pt-Pd, Pt-I species in the PtPd (111) alloy systems, respectively.

\begin{tabular}{cc}
\hline Species & distance $(\AA)$ \\
\hline & Pt-Pt: 2.731 \\
& Pt-Pd: 2.748 \\
$\mathrm{Pt}_{1} \mathrm{Pd}_{9}(111)$ & Pt-I: $2.693 ;$ Pd-I: 2.687 \\
\hline $\mathrm{Pt}_{3} \mathrm{Pd}_{7}(111)$ & Pt-Pt: 2.758 \\
& Pt-Pd: $2.750 ; 2.760$ \\
& Pt-I: $2.692 ;$ Pd-I: 2.667 \\
\hline $\mathrm{Pt}_{5} \mathrm{Pd}_{5}(111)$ & Pt-Pt: 2.722 \\
& Pt-Pd: 2.585 \\
& Pt-I: $2.695:$ Pd-I:2.624 \\
\hline $\operatorname{Pt}_{7} \mathrm{Pd}_{3}(111)$ & Pt-Pt: 2.730 \\
& Pt-Pd: 2.736 \\
& Pt-I: $2.697 ;$ Pd-I: 2.594 \\
\hline
\end{tabular}

Table S5. Adsorption energies of $I_{2}$, desorption energies of $I^{-}$, corresponding absolute energies and optimized geometries calculation of iodine in PtPd (111) planes.

\begin{tabular}{cccc}
\hline Systems & $\begin{array}{c}\mathbf{E}_{\mathbf{a d}} \\
(\mathbf{e V})\end{array}$ & $\begin{array}{c}\mathbf{E}_{\mathbf{d e}} \\
(\mathbf{e V})\end{array}$ & $\begin{array}{c}\mathbf{E}_{\mathbf{a b s}} \\
(\mathbf{e V})\end{array}$ \\
\hline $\mathrm{Pt}_{1} \mathrm{Pd}_{9} \mathrm{NC}$ & -1.25 & 2.31 & 1.06 \\
$\mathrm{Pt}_{3} \mathrm{Pd}_{7} \mathrm{NC}$ & -1.1 & 2.14 & 1.04 \\
$\mathrm{Pt}_{5} \mathrm{Pd}_{5} \mathrm{NC}$ & -1.1 & 2.11 & 1.01 \\
$\mathrm{Pt}_{7} \mathrm{Pd}_{3} \mathrm{NC}$ & -1.15 & 2.17 & 1.02 \\
\hline
\end{tabular}




\section{Reference}

1. Wan, J.; Fang, G.; Yin, H.; Liu, X.; Liu, D.; Zhao, M.; Ke, W.; Tao, H.; Tang, Z., Pt-Ni Alloy Nanoparticles as Superior Counter Electrodes for Dye-Sensitized Solar Cells: Experimental and Theoretical Understanding. Adv. Mater. 2014, 26, 8101-8106. 2. Kuhlenbeck, H., Metal-Surface Reaction Energetics. Theory and Applications to Heterogeneous Catalysis, Chemisorption, and Surface Diffusion. Herausgegeben von E. Shustorovich. VCH Publishers, New York/VCH Verlagsgesellschaft, Weinheim, 1991. XII, 232 S., geb. 144.00 DM. - ISBN 0-89573-776-0/ 3-527-27938-5. Angew. Chem. 1993, 105, 321-322. 